\title{
A prisão fora e acima da lei
}

Rafael Godoi*

http://orcid.org/0000-0002-1363-6134

Introdução

Neste artigo, debruço-me sobre os relatórios de inspeção elaborados pela Defensoria Pública do Rio de Janeiro no âmbito de seu programa de monitoramento do sistema carcerário estadual. Detenho-me, sobretudo, em relatos que versam sobre formas de interação e relação entre agentes de fiscalização e autoridades prisionais no decurso das vistorias e em alguns de seus mais significativos desdobramentos. Pretendo, assim, explorar os jogos de poder que se estabelecem entre essas duas particulares agências estatais que, cada uma a seu modo, reivindicam o papel de garantir o império da lei em nossa sociedade: a prisão, pedra angular do direito penal; e a Defensoria Pública, agência fundamental para a democratização do acesso à justiça e para a garantia dos direitos humanos, civis, políticos, sociais e processuais das parcelas mais vulneráveis da população.

Em sua revisão das pesquisas empíricas sobre prisão, e tomando como questão central a articulação entre os mundos de dentro e de fora dos muros, Cunha (2014) mostra como muitos estudos têm avançado em duas direções principais. De um lado, os trabalhos se voltam para "o funcionamento da instituição" e colocam práticas e agentes institucionais em primeiro plano; de outro, tematizam a "prisão além dos muros", com análises mais centradas nos presos e em seu mundo social ampliado, nas

* Universidade Federal do Rio de Janeiro, Rio de Janeiro, Brasil. 
relações que mantêm com amigos e familiares, vizinhos e comunidades. Conforme a autora, tanto numa, quanto noutra direção, diversos trabalhos vêm mostrando um processo de progressiva erosão das fronteiras prisionais.

No que se refere ao funcionamento da instituição - o plano de análise em que esta pesquisa se insere ${ }^{1}$-, o trasbordamento da prisão se dá sobre um eixo vertical, mais escalando estruturas de poder, que difundindo efeitos sobre o tecido social. A erosão das fronteiras se manifesta, então, como um deslocamento dos centros de poder e decisão para fora da prisão e para estratos mais altos da burocracia administrativa. As análises recaem, assim, sobre processos de centralização das cadeias de comando, de padronização de procedimentos e de condições de confinamento, de burocratização de rotinas e processos decisórios, que retiram do interior dos muros e das mãos daqueles que dirigem as prisões, no dia a dia, muito do poder discricionário que historicamente lhes era outorgado.

Barak-Glantz (1981) foi um dos primeiros a chamar a atenção para esse gradual processo de transição, nos Estados Unidos da segunda metade do século Xx, de um modelo autoritário e mais tradicional de gestão penitenciária para outro, mais moderno e de caráter burocrático-legal. Jacobs (1980), por sua vez, mostrou como tal processo resultou, em grande medida, do movimento pelos direitos dos presos, que, entre os anos 1960 e 1980, adotara a mesma estratégia de litigância judicial empregada no movimento pelos direitos civis. Para esse autor, se por um lado as diversas vitórias judiciais desse movimento levaram à melhoria significativa das condições de vida no cárcere, por outro, acarretaram uma rígida burocratização das rotinas prisionais e uma intensificação do controle sobre a população carcerária ${ }^{2}$. A evolução do direito penitenciário em diversos outros países ocidentais, nas últimas décadas do século xx, também ensejou análises que trazem essas mesmas questões de fundo: a estruturação de um novo modelo de gestão penitenciária, que, fundado na lei e outorgando direitos aos reclusos, acaba por revigorar uma combalida prisão (Kaminski 2002; Chantraine e Kaminski, 2008).

1. Meu trabalho anterior (Godoi, 2017a) se situa na intersecção dos dois referidos campos de problematização, uma vez que exploro como o caráter progressivo e jurisdicionalizado das penas no Brasil acaba por instaurar uma espécie de governo à distância da população carcerária, que depende tanto da colaboração ativa do staff prisional como da mobilização contínua das redes ampliadas que articulam presos, amigos e familiares, dentro e fora dos muros. A investigação aqui proposta pressupõe tal regime de processamento da execução penal e procura avançar para outras dimensões da relação entre sistema de justiça e prisão.

2. Tal observação de Jacobs funda um amplo e rico debate sobre os efeitos paradoxais dessa "entrada" do direito nas prisões estadunidenses, seja para o progressivo recrudescimento do tratamento (Feeley e Swearingen, 2004), seja para o próprio processo de massificação do encarceramento (Schoenfeld, 2010; Simon, 2013; Guetzkow e Schoon, 2015). Para uma análise de processos de legalização de tratamentos desumanos no Brasil, ver Teixeira (2009). Para uma abordagem dos nexos entre esforços de humanização e expansão do parque penitenciário em São Paulo, ver Marques (2019). 
Sem perder de vista os rendimentos desse tipo de transição para a vitalidade da prisão, quero aqui ressaltar, sobretudo, que a questão da erosão das fronteiras prisionais que se desdobra pelo deslocamento dos centros de poder para fora e para cima está histórica e empiricamente associada ao problema da "entrada" do direito no cárcere, em particular dos direitos humanos. "Entrada" que pode viabilizar-se por intervenções judiciais ou por reformas legislativas, mas que sempre se elabora como uma forma de limitar o poder de punir pelas injunções da lei, de promover a dignidade dos presos, de melhorar condições de confinamento e racionalizar as formas de tratamento. É neste sentido que aqui me proponho a descrever e analisar uma particular modalidade de "entrada" da lei e dos direitos humanos nas prisões fluminenses: via programa de monitoramento do sistema carcerário da Defensoria Pública.

\section{Objeto e método}

Desde que o artigo $5^{\circ}$ da Declaração Universal dos Direitos Humanos, de 1948, proscreveu a tortura e outros tratamentos ou penas cruéis, desumanos e degradantes, diversos foram os esforços que se empreenderam para dar corpo a tal injunção. Entre os mais notáveis constam o estabelecimento das Regras Mínimas para o Tratamento dos Reclusos, de 1955³ , e a Convenção contra a Tortura, de 1984; também a estruturação das comissões e comitês de prevenção à tortura e das cortes internacionais de direitos humanos, no âmbito das Nações Unidas (ONU), do Conselho Europeu (CE) e da Organização dos Estados Americanos (OEA). Mais recentemente, a partir de uma avaliação crítica dos limites de tal sistema de proteção, a oNU, por meio do Protocolo Facultativo à Convenção contra a Tortura (Opcat, na sigla em inglês) passou a promover a criação de um sistema de visitas periódicas a espaços de privação de liberdade, a serem feitas tanto pelo seu Subcomitê de Prevenção à Tortura (SPT), quanto por Mecanismos Preventivos Nacionais (MPN) a serem criados ou designados em cada país signatárió.

No Brasil, conforme a legislação vigente, funções de fiscalização dos espaços de reclusão podem ser exercidas por juízes, promotores e defensores públicos, além dos Conselhos da Comunidade, dos Conselhos Penitenciários estaduais, do Conselho Nacional de Política Criminal e Penitenciária (CNPC) e do Departamento Penitenciário Nacional (DEPEN). Ademais, existem organizações da sociedade civil, como a Pastoral Carcerária, que historicamente desenvolvem trabalhos independentes

3. Atualizadas em 2015 e rebatizadas como Regras de Mandela.

4. Para uma detalhada reconstituição desse processo e de seus desdobramentos em diferentes partes do mundo, ver Morgan (2000), Zyl Smit (2010) e Cliquennois e Snacken (2018). 
de monitoramento (Salla, 2005). Com a adesão ao Opcat, em 2013, os espaços de reclusão do país também passaram a ser fiscalizados pelo sPT, pelo Mecanismo Nacional de Prevenção e Combate à Tortura (MNPCT) e, em diversas unidades da federação, por mecanismos preventivos estaduais5.

No estado do Rio de Janeiro, o Tribunal de Justiça (TJRJ) mantém um Grupo de Monitoramento e Fiscalização do Sistema Carcerário, e o Ministério Público (MP) desenvolve o projeto Luz no Cárcere - ambos realizando vistorias e divulgando dados com regularidade ${ }^{6}$. O estado dispõe ainda, desde 2010, de seu pioneiro Mecanismo Estadual de Prevenção e Combate à Tortura (МЕPCT); além de contar com a mais antiga e uma das mais bem equipadas Defensorias Públicas do país (cf. Cejus, 2015) - a qual desenvolve o seu próprio programa de monitoramento do sistema carcerário estadual, por meio de seus núcleos especializados de Defesa dos Direitos Humanos (NUDEDH) e do Sistema Penitenciário (Nuspen). Esses órgãos monitoram um sistema carcerário que, em junho de 2016, era composto por 51 unidades, que dispunham de 28.443 vagas, mas abrigavam 50.219 pessoas - sendo $95 \%$ delas do sexo masculino, $72 \%$ negras, $59 \%$ com idades entre 18 e 29 anos e $40 \%$ que ainda não haviam sido julgadas (DEPEN, 2016).

Foram-me disponibilizados, via Lei de Acesso à Informação, 40 relatórios referentes a 43 inspeções feitas pela Defensoria Pública, entre os anos de 2015 e 2017, em 33 unidades prisionais geridas pela Secretaria de Estado de Administração Penitenciária (Seap) e espalhadas pelas diversas regiões do estado ${ }^{7}$. Essas inspeções foram feitas por uma equipe composta por defensores, estagiários, outros servidores dos núcleos especializados e arquitetos do setor de Engenharia Legal da Defensoria. Segundo os relatos, as visitas consistiam numa conversa inicial com a direção da unidade, seguida de vistoria nos diferentes espaços da prisão, de entrevistas reservadas com os reclusos, podendo, por vezes, se desdobrar em novos contatos com determinados setores da administração penitenciária.

Em linhas gerais, cada "Relatório de Visita à Unidade Prisional" analisado registra: nome e endereço da unidade inspecionada; os defensores e auxiliares que realizaram a inspeção e os dispositivos legais que fundamentam a fiscalização; as características da unidade, a facção hegemônica, a capacidade oficial e a população reclusa no dia; a divisão interna do espaço prisional, com descrição de celas e galerias; as dinâmicas de

5. Cabe mencionar aqui que a conformidade do Brasil ao Opcat está em questão desde a publicação do decreto 9.831, de 10 de junho de 2019, pelo qual o presidente Jair Bolsonaro praticamente inviabiliza o funcionamento do MNPCT.

6. Para mais informações, ver http://gmf.tjrj.jus.br/ e http://apps.mprj.mp.br/sistema/lzca, consultados em 14/8/2019.

7. Tal acervo não corresponde à totalidade das inspeções realizadas pela Defensoria no período de referência. 
banho de sol, fornecimento de água e alimentação; os serviços técnicos reportados pela direção, especificando número de profissionais e frequência de atendimentos; oportunidades de estudo, trabalho e lazer; efetivo de servidores por plantão e suas condições de alojamento e trabalho; dinâmica de visitação familiar e íntima; observações decorrentes das entrevistas com os presos; considerações gerais; e, finalmente, recomendações. Conforme esclarecimentos prestados pela coordenação do Nuspen, cada relatório demora cerca de um mês para ser feito e é encaminhado por correio eletrônico à própria unidade, à Seap, à Vara de Execuções Penais (VEP), ao MP e a outras autoridades dos poderes executivo, legislativo e judiciário.

Seguindo de perto a estrutura dos relatórios, construí uma tabela na qual sintetizei informações referentes à estrutura física de cada unidade, às dinâmicas de tratamento vigentes e às circunstâncias de cada inspeção - sobre essas últimas que me detenho neste trabalho. A análise desse material vem sendo de todo qualitativa; informada por contribuições epistemológicas e teóricas de uma antropologia do estado que se volta para as práticas documentárias e os registros documentais como expedientes estratégicos e reveladores de dispositivos estatais de gestão de populações (Das, 2007; Gupta, 2012); também por proposições teóricas e metodológicas de uma emergente sociologia empírica dos usos do direito na prisão (Salle e Chantraine, 2009; Galembert e Rostaing, 2014). Assim, exploro aqui relatos de práticas, enunciados e interações que evocam e instanciam, de diferentes modos, o direito, a lei e a autoridade no interior do cárcere e que desenham um campo de lutas, resistências e negociações que não são necessariamente jurídicas, nem estão circunscritas apenas ao interior das prisões.

No que segue, tomo um relatório em particular como fio condutor da análise e evoco outros conforme as necessidades da exposição. $\mathrm{O}$ documento escolhido se destaca por relatar não uma, mas duas inspeções, cada uma delas muito diferente da outra: a primeira sendo a mais tensa das visitas relatadas no acervo que me foi disponibilizado. Tal escolha se justifica não só porque, nesse documento, as circunstâncias de inspeção ocupam lugar de destaque, mas principalmente porque o caso-limite, por seu caráter raro e exagerado - assim como num tipo ideal - revela muito do que se apresenta atenuado nas circunstâncias mais ordinárias.

A lei diante da lei

O "Relatório de Visita à Unidade Prisional" Evaristo de Moraes, que tomo como fio condutor desta exposição, registra duas inspeções realizadas nessa unidade nos dias 30 de abril e 12 de maio de 2015. No primeiro dia, a equipe da Defensoria teve o seu trabalho de fiscalização bastante prejudicado pela direção da unidade. Por isso, 
os defensores retornaram dias depois, acompanhados por um promotor de justiça e pelo MEPCT, quando puderam fazer a inspeção normalmente. Numa seção que só existe nesse relatório se lê:

II) EMbaraços Criados Pela direção para realização da ViStoria NO dia 30 DE ABRIL DE 2015

No dia 30 de abril de 2015, a equipe da Defensoria Pública chegou à Unidade Evaristo de Moraes às $12 \mathrm{~h} 25$ e não teve sua entrada permitida imediatamente como ocorrera até então em todas as Unidades vistoriadas pela Defensoria Pública no ano de 2015. O agente penitenciário que estava na portaria da Unidade nos informou que teríamos que esperar a chegada do Diretor para termos nossa entrada franqueada. Após 25 minutos de espera e muita insistência, foi permitida a entrada até o prédio da direção, onde aguardamos por mais vinte minutos até sermos recepcionados pelo Diretor que exercia o cargo na época, Sr. [NOME], que não permitiu que a vistoria fosse feita imediatamente conforme solicitado, sob o argumento de que era mais apropriado prestar algumas informações antes de iniciar a visita.

Dessa forma, só foi franqueada a entrada da equipe da Defensoria Pública nas galerias da unidade prisional às $14 \mathrm{~h}$, ou seja, mais de $1 \mathrm{~h}$ e $30 \mathrm{~min}$ após o anúncio da nossa chegada ${ }^{8}$.

Comumente, as inspeções da Defensoria ocorrem sem aviso prévio. Este é um requisito técnico para uma política de prevenção e combate à tortura que pretende surpreender autoridades e flagrar violações e que, seguindo uma lógica tipicamente disciplinar, visa à internalização da conformidade naqueles sobre os quais exerce a vigilância. Como ensina Foucault (2014), tão ou mais eficaz que a vigilância contínua sobre um determinado sujeito, é o fato de o vigiado saber que pode ser observado a qualquer momento, sem poder determinar quando de fato o é. Não por acaso, a estruturação de um vasto dispositivo transnacional de regulação de condições de confinamento e tratamento penitenciário baseado em mecanismos de inspeção in loco leva Cliquennois e Snacken (2018) a questionarem se não estaríamos testemunhando a constituição de um verdadeiro "panóptico invertido". Malvezzi Filho (2018), por sua vez, sugere que esse tipo de arranjo se funda sobre uma concepção criminológica da tortura como um crime de oportunidade, como conduta individual fruto de cálculo e, portanto, passível de dissuasão. Entretanto, num contexto em que a tortura se apresenta de forma difusa e continuada (Godoi, 2017b), em que ela se mostra um aspecto constitutivo e imediato das próprias condições de confinamento, um mecanismo preventivo que pretende assim dissuadir torturadores só pode gerar “efeitos efêmeros ou puramente cosméticos" (Malvezzi Filho, 2018, p. 85).

8. Nas citações, mantenho todos os destaques originais e preservo as identidades de funcionários e presos. 
Embora a entrada da equipe da Defensoria costume ser "permitida imediatamente" em "todas as unidades", o empenho da direção do Evaristo em retardar o início da fiscalização e, assim, reduzir o seu efeito surpresa indica a resistência da prisão ao escrutínio externo de suas instalações. Outros "embaraços criados" pela administração penitenciária permitem aprofundar essa leitura:

Ressalte-se que, ao ser informado de que seria utilizado material fotográfico na realização do trabalho, o diretor disse que não permitiria, em total desrespeito à resolução do Conselho Nacional de Política Criminal e Penitenciária, que permite expressamente a utilização de instrumentos de registros audiovisual e fotográfico em vistorias realizadas em unidades prisionais.

O diretor alegou que seria necessária autorização do titular da Secretaria de Administração Penitenciária - Seap e voltou para sua sala por dois minutos e retornou dizendo que não conseguiu fazer contato telefônico e que por isso o uso de máquinas fotográficas não estava permitido.

A entrada de câmera fotográfica no interior dos presídios é a mais frequente causa de controvérsias relatadas entre a equipe de inspeção da Defensoria e as autoridades prisionais fluminenses. Como no trecho citado, nessas ocasiões, os defensores invariavelmente evocam a resolução n. 1, de 7 de fevereiro de 2013, do CNPCP, enquanto os gestores prisionais costumam recorrer a autoridades administrativas superiores. No relatório de inspeção feita à Penitenciária Laercio da Costa Pelegrino, em 17 de maio de 2016, a entrada da câmera fotográfica só foi permitida após a autorização expressa do "coordenador geral" do Complexo de Gericinó. Na inspeção feita em 22 de junho de 2016, no Presídio Nilza da Silva Santos, em Campos dos Goytacazes, a entrada da câmera fotográfica também só foi possível após a autorização da “Coordenação Regional” da Seap; e no Presídio Milton Dias Moreira, em 19 de abril de 2016, ela só foi possível após a espera de quarenta minutos por uma autorização expressa do "subsecretário adjunto de gestão operacional da Seap".

Enquanto a Defensoria recorre a um texto legal, o gestor prisional busca respaldo numa palavra de autoridade: eis uma dinâmica central e constitutiva da relação conflituosa entre o mecanismo de fiscalização e as prisões fluminenses. Uns se apoiam na palavra escrita das resoluções, dos tratados internacionais e da legislação penal - na letra da lei, em suma; outros se valem da palavra dita de uma autoridade superior - o "coordenador", o "subsecretário adjunto", o "titular”. A relação entre equipe de inspeção e staff prisional pode ser entendida como essa espécie de embate entre uns que empunham a lei e outros que exercem autoridade. 
Antes de desdobrar essas figurações da lei e da autoridade, é importante destacar que a autorização para o registro de imagens de dentro das unidades, ainda que demore um pouco, costuma vir. Portanto, se é verdade que, de um lado, as reticências impostas pela direção de uma unidade convertem a entrada da máquina fotográfica numa demonstração de força da equipe de fiscalização, numa pequena vitória da Defensoria; por outro lado, a frequente autorização concedida indica que as imagens que a Defensoria registra não representam tamanho risco para a administração penitenciária. Ao analisarem esse mesmo programa de monitoramento, Stanchi e Dias (2018, p. 10) ressaltam o fato de a Defensoria não disponibilizar publicamente seus relatórios - e, portanto, as fotos - como um fator decisivo para "a continuidade e funcionalidade dos programas de vistoria", mas lembram que tal escolha acaba por reproduzir "a tônica do silêncio" característica da prisão. O mesmo pode ser afirmado sobre o fato de a Defensoria ter excluído todas as fotografias dos relatórios que me foram disponibilizados para esta pesquisa. Ou seja, assim como a prisão procura exercer algum controle sobre as imagens que se registram em seu interior, a Defensoria também procura controlar o emprego das imagens que produz no decorrer das inspeções. Tais preocupações compartilhadas não só denotam a carga política que essas imagens de dentro podem adquirir do lado de fora - se usadas como provas judiciais, peças jornalísticas, ou material de pesquisa, por exemplo -, como indicam a existência de um mínimo e necessário patamar de colaboração entre as partes para que um programa de monitoramento como esse possa se sustentar.

Observando apenas os primeiros contatos entre a equipe de fiscalização e o corpo de funcionários da prisão, é possível perceber como entre esses dois coletivos não existe uma relação de puro constrangimento, nem de total alinhamento, mas sim formas de embate e colaboração, negociações assimétricas, investidas e resistências, coerções diretas e concessões veladas - relaçôes de poder, portanto: este o objeto principal desta investigação.

\section{Corpo a corpo}

O relato daquela infeliz visita ao Evaristo continua nos seguintes termos:

Os entraves para a realização da vistoria não pararam por aí.

Não bastasse isto, o Diretor fez questão de deslocar cerca de 7 (sete) agentes para acompanhar a vistoria, colocando-os lado a lado da equipe da Defensoria, intimidando os presos e fiscalizando o que eles falavam.

A direção apresentou um itinerário a ser seguido na visita, não permitiu que a Defensoria Pública tivesse acesso irrestrito às celas, determinou que os agentes penitenciários entrassem 
nas celas junto com a equipe, o que tornou impossível qualquer momento de privacidade com os presos. Além disso, só autorizou que fosse aberta uma cela por galeria.

O diretor também entrava nas celas de modo a não deixar os presos à vontade para dialogar com a Defensoria Pública.

Ao ser informado que sua postura estava inviabilizando o trabalho, o diretor permitiu apenas que alguns presos fossem retirados de suas celas para uma conversa coletiva em um local um pouco afastado. Ainda assim os agentes penitenciários ficavam rondando o grupo e o trabalho permaneceu maculado.

Apesar de todas as tentativas de intimidar e atrapalhar a vistoria, vários presos informaram que antes de a equipe entrar na Unidade os agentes penitenciários passaram nas celas avisando que a Defensoria Pública iria entrar no estabelecimento prisional e que eles só deveriam reclamar do próprio atendimento da Defensoria Pública e que qualquer outro tipo de reclamação não deveria ser feito, sob pena de retaliação.

Ressalta-se que ao perceber que os estagiários da Defensoria Pública estavam conseguindo várias informações com os presos que desagradavam à direção, o Diretor, que estava naquela ocasião no cargo, Sr. [NOME] proibiu que os estagiários tivessem autonomia dentro do presídio, exigindo que os mesmos ficassem o tempo todo ao lado de um Defensor Público, mesmo após ter sido esclarecido que os estagiários têm essa função e são treinados para isso. Por volta das 15 h, ou seja, apenas 1 hora depois da entrada da Defensoria nas galerias, o Diretor disse que deveríamos acabar logo com a visita para não atrapalhar a rotina do presídio.

O excerto sumaria as diversas maneiras pelas quais o staff prisional pode "macular" o trabalho de fiscalização. Além de retardar a entrada e proibir o registro de imagens, ele pode ameaçar os presos, intimidar a equipe de inspeção, constranger e vigiar as conversas entre uns e outros, estabelecer o itinerário para a visita, restringir a circulação dos diversos membros da equipe, limitar o acesso a determinados espaços da prisão, além de pôr termo à vistoria quando bem entender. $\mathrm{O}$ relato acima é particularmente interessante também porque coloca em evidência um complexo jogo de forças e de inversões, no qual os fiscalizados aparecem fiscalizando a fiscalização. Ganha relevo, assim, de um lado, o poder quase absoluto da prisão e do seu staff sobre a circulação e a comunicação dentro dos seus domínios, e por outro, a fragilidade da equipe de inspeção, sua radical dependência do consentimento daquele que é fiscalizado e que dispõe de todos os meios para "macular" o seu trabalho. Diante da hostilidade de uma gestão prisional que pode "intimidar" "determinar", "constranger" e "atrapalhar", resta aos defensores o exercício diplomático de procurar "informar", "esclarecer", "requisitar".

Desse modo, enquanto o gestor prisional - aquele que, como já apontado, tende a se apoiar sobre a palavra de autoridade - parece se valer amplamente da força física, a 
equipe da Defensoria - que procura reivindicar a validade da letra da lei - se mostra absolutamente débil, sem condições de impor o menor curso de ação. A fraqueza da lei e a força da autoridade são as figurações que agora emergem representando os coletivos que se defrontam no decurso de uma inspeção e que considero importante reter. Mas tão importante quanto reter essas imagens gerais é seguir desdobrando-as, pois o fraco pode por vezes se fazer forte, e o forte pode, vez ou outra, se dobrar - e tais inflexões também ensinam sobre as qualidades e relações de uns e outros.

Se, numa visita, a equipe da Defensoria encarna a letra da lei - e isso de uma maneira absolutamente precária diante da força da autoridade administrativa -, é preciso considerar que essa instanciação da lei também se faz por meio da palavra falada - da palavra de autoridade dos próprios defensores. Assim como ocorre com a permissão para a entrada de uma máquina fotográfica no presídio, a existência e a validade das leis escritas alhures também precisam ser evocadas, enunciadas e verbalizadas in loco por alguém autorizado. Nesse sentido, como a palavra de autoridade, a letra da lei é também instanciada num ato de fala (Austin, 1962). Mesmo sob as circunstâncias particularmente adversas da visita ao Evaristo, a enunciação da lei pela equipe da Defensoria ainda pôde se mostrar dotada de alguma eficácia. Na seção "Aspecto interno" do relatório se lê:

\begin{abstract}
Ainda no primeiro dia de vistoria as celas 8 e 9 do isolamento estavam sem luz em seu interior e segundo o Sr. [NOME], que exercia o cargo de Diretor, os presos vendiam as lâmpadas e por esta razão as celas estavam escuras. Porém, quando pedimos para abrir as celas pôde-se observar que na verdade as lâmpadas estavam queimadas. Solicitada ao Diretor a troca das lâmpadas, o mesmo respondeu que o Estado não havia fornecido e que isso não seria possível. Ao ser advertido sobre o $\$ 2^{\circ}$ do art. 45 da LEP, o Diretor imediatamente providenciou a colocação de lâmpadas nestas duas celas do isolamento.
\end{abstract}

De algum modo, a evocação da lei pelos defensores foi capaz de coagir o mais relutante dos gestores prisionais. Conforme a sequência do relato, os defensores ainda conseguiram que o diretor determinasse a remoção dos presos que estavam na cela ao lado, inundada por um entupimento no banheiro. Encontrando essa mesma cela ainda alagada e novamente ocupada na segunda visita, a equipe de inspeção repetiu o feito. E no relatório de uma terceira inspeção nesse mesmo Evaristo, datada de 11 de abril de 2017, há o registro de que, no decorrer de uma "revista geral", os funcionários deixaram de obrigar "as presas transexuais e travestis" a ficarem nuas "ao lado dos internos e na frente de vários agentes”, após a advertência dos defensores sobre a violação ao artigo $7^{\circ}$ da resolução $558 / 15$ da própria Seap - o que mostra que não são apenas as letras distantes dos tratados internacionais de direitos humanos que 
a Defensoria procura fazer valer no interior do cárcere, mas também as normativas da própria administração penitenciária.

Situações como essas remetem aos efeitos "efêmeros e cosméticos" que uma inspeção pode ter e que foram criticados por Malvezzi Filho (2018). Sem sobrestimar a demonstração de força da Defensoria nessas ocasiões, quero ressaltar que tais pequenas - e imediatamente reversíveis - vitórias interessam porque mostram como a equipe de inspeção, apesar de suas debilidades estruturais, pode vir a coagir os gestores prisionais a cumprirem determinadas leis, ainda que temporariamente - e, como se vê, a presença física no interior do cárcere, o ato de enunciação e alguma insistência são fatores decisivos.

Em relatos mais raros e mais contundentes que essas breves refregas entre staff e equipe da Defensoria, outras formas de o fraco se fazer forte no decorrer de uma inspeção ganham relevo. Depois de documentar extensamente o "Aspecto interno" do Evaristo, o relatório traz o seguinte apartado:

\section{XVi) DenúnCia de Agressónes Contra O CHEFE de SEguranÇa}

No dia 12 de maio de 2015, o interno [NOME], RG [NÚMERo], narrou ter sofrido agressões físicas e ameaças por parte do Chefe de segurança, Sr. [NOME], e que desejava registrar ocorrência dos fatos. Segundo o interno, tais agressões ocorreram na sala de Serviço de Segurança que foi vistoriada pela equipe e constatado que não possui circuito interno de TV para capturar as imagens do local. Os membros do Mecanismo de Combate à Tortura presentes na vistoria informaram que, em visita anterior feita nesta Unidade, outro detento narrou ter sido agredido neste mesmo local e que, mesmo após postularem a colocação de câmara de filmagem no local, nada foi feito. Ao final da vistoria, acompanhamos o interno à sala da direção para narrar os fatos e foi determinada, pelo Diretor a abertura de uma sindicância. Acompanhamos o interno até a $74^{a}$ Delegacia de Polícia, onde os fatos foram registrados e o interno transferido para o Presídio Bandeira Stampa.

No relatório de inspeção feita na Penitenciária Jonas Lopes de Carvalho, no Complexo de Gericinó, em 19 de janeiro de 2016, tem-se, em linhas gerais, esse mesmo procedimento registrado para formalização e encaminhamento de denúncia de tortura feita por dois internos. Nessas situações, à afirmação da vigência da lei feita pelos defensores se soma outro ato de fala fundamental: a acusação feita pelos reclusos. Em todas as inspeções relatadas, os presos são ouvidos reservadamente e se queixam copiosamente dos mais diversos aspectos da estrutura e do tratamento prisional; muitos, inclusive, relatam agressões sofridas num passado mais ou menos remoto, chegando a indicar determinados funcionários especialmente violentos. Mas o curso normal de uma inspeção só muda quando alguns poucos reclusos expressam 
o desejo de formalizar, ali mesmo no ato da inspeção, a denúncia de que foram ou estão sendo torturados por um ou mais funcionários.

A partir desse primeiro acoplamento entre as palavras de defensores e defendidos, no jogo de relações entre equipe de inspeção e staff prisional, formas de negociação e de demonstração de força passam a se confundir nos mesmos atos. Conflito e colaboração se mostram, então, não só aspectos indissociáveis, mas absolutamente indiscerníveis. Como se houvesse uma total inversão das relações de poder entre os dois coletivos, a Defensoria passa a ditar amplamente o rumo dos acontecimentos. Mas vale notar que, do começo ao fim, o processo de formalização da denúncia só se realiza com a anuência e a participação das autoridades prisionais. A direção não só acolhe a denúncia e instala "sindicância" para apurar os fatos, como providencia a escolta do preso para ele depor na delegacia e trata da sua transferência com a administração penitenciária. Ou seja, aqui também, como no caso da instalação de uma lâmpada numa cela escura ou da interdição de uma cela alagada, a equipe de inspeção enreda o staff prisional num determinado curso de ação que visa à imediata aplicação de certas determinações legais.

Para além da denúncia da vítima, da presença da Defensoria e da colaboração do staff, a formalização da denúncia de tortura depende ainda do envolvimento de outros atores compondo um agenciamento mais amplo, que ultrapassa os muros da prisão e alcança outros estratos da hierarquia administrativa estatal - como numa verdadeira "escalada” para fora e para cima dos limites prisionais. A denúncia se apresenta, então, como a resultante de uma ampla arregimentação de forças que a Defensoria articula e mobiliza, dentro e fora dos muros: à palavra do preso se somam as evocações da Defensoria sobre os textos legais; estes reclamos são postos à direção da unidade, que reage - administrativamente - abrindo sindicância e cuidando para que preso e defensores possam apresentar suas alegações em sede policial; a polícia judiciária então toma conhecimento da denúncia e instaura algum procedimento de investigação; assim como "coordenadores", "subsecretários” e "titulares” da Seap se veem, então, envolvidos na tarefa de providenciar uma mais adequada destinação ao sujeito em questão, além dos meios para a sua transferência. A articulação e a mobilização dessa vasta rede explicam como as leis que proscrevem a tortura e regem o tratamento dos reclusos podem eventualmente "entrar" nas prisões fluminenses para fazer cessar uma ilegalidade - mostrando como o fraco pode ficar forte, em suma.

Essas mesmas dinâmicas de articulação e mobilização, de enredamento e acumulação de agências várias, ultrapassando perímetros e escalando hierarquias, se mostram fundamentais naquelas ocasiões em que a equipe da Defensoria se vê obrigada a ceder diante da intransigência de determinados gestores prisionais - para em seguida, voltar à carga com novas forças. Tal foi a manobra da instituição quando 
retornou ao Evaristo dias depois de ter sua inspeção "maculada" pelo diretor, mas acompanhada, então, pelo МЕРСт e por um promotor de justiça - que, vale lembrar, ao contrário dos defensores, detém prerrogativas de indiciamento e incriminação. Manobra análoga se registra no relatório das vistorias feitas nos dias 17 e 18 de março de 2015, na Cadeia Pública José Frederico Marques. Na primeira visita, a equipe da Defensoria identificou dezenas de presos recém-transferidos com claros sinais de espancamentos e, por isso, voltou no dia seguinte na companhia de um promotor de justiça, para formalizar denúncias e forçar a tomada de providências imediatas como, por exemplo, a remoção dos presos mais debilitados para tratamento médico e a distribuição de dezenas de colchões aos recém-chegados.

Embora raros, tais processos e agenciamentos, ao interromperem situações potenciais ou concretas de graves violações de direitos, indicam que o programa de monitoramento do sistema carcerário da Defensoria - se não é de todo apropriado para prevenir maus tratos num sistema carcerário tão deteriorado quanto o fluminense - constitui, sim, um meio disponível para o combate à tortura - gerando efeitos que, embora possivelmente "efêmeros", não podem ser desqualificados como "cosméticos".

\section{Para fora e para cima}

Questões sobre o destino das sindicâncias, dos inquéritos e dos presos que decidiram formalizar as denúncias de tortura, embora decisivas, não podem ser respondidas com esta pesquisa9. O material aqui analisado permite apenas identificar algumas das condições de possibilidade para essa atípica, mas significativa demonstração de força da equipe da Defensoria, em particular aquele esforço de articulação e mobilização de uma ampla rede, que se estende para fora e para cima da unidade vistoriada, arregimentando normas, leis, discursos, instituições e atores, de escalas e naturezas variadas. Pretendo agora explorar alguns modos pelos quais os próprios relatórios aqui analisados se enredam numa trama como essa, mas ainda mais vasta, que se estende por territórios mais amplos e alcança hierarquias mais altas, e que é continuamente mobilizada justamente para fazer "entrar" o direito nas prisões fluminenses. Ou seja, procuro divisar nos relatórios pistas sobre em que outros planos se desdobram os esforços de articulação e mobilização da Defensoria e quais destinos eles podem ter.

Como já indiquei, todos os relatórios trazem informações sobre a política de acesso ao banho de sol que vigora na unidade vistoriada. Comumente, a direção

9. Para uma análise de como o sistema de justiça criminal brasileiro tende a tratar denúncias de tortura, ver Jesus (2010) e Jesus et al. (2016). 
informa certa dinâmica; os internos relatam outra totalmente diferente; a equipe da Defensoria registra ambas as versões e assinala que qualquer uma delas contraria o direito ao banho de sol estabelecido em leis e tratados internacionais - de uma forma ou de outra, a frequência e a duração são insuficientes, os espaços não possibilitam uma satisfatória incidência de luz natural, nem comportam a realização de exercícios físicos. Nesse quesito, o sistema carcerário fluminense como um todo está "fora da lei”. A partir do relatório da visita ao Presídio Ary Franco, de 9 de junho de 2015, a sempre presente recomendação para adequação da política de acesso ao banho de sol na unidade vistoriada passou a se repetir nos seguintes - e truncados - termos:

16. Observância ao direito dos internos ao BANHO DE SOL DIÁRIO, por no mínimo 1 HORA, em local aberto e adequado à prática de atividade física em respeito, INCLUSIVE AOS PRESOS DAS CELAS DE ISOLAMENTO, não só em observância ao art. 21 das Regras Mínimas para o Tratamento de Reclusos, adotada no $1^{\circ}$ Congresso das Nações Unidas sobre Prevenção do Delito e Tratamento do Delinquente, celebrada em Genebra no ano de 1955 e aprovada pelo e ao art. 14 da Resolução no 14/94 do Conselho Nacional de Política Criminal e Penitenciária (CNPCP) do Mistério da Justiça, que ao fixar as Regras Mínimas para o Tratamento do Preso no Brasil Conselho Econômico e Social das Nações Unidas, através das Resoluções 663C de 1957 e 2076 de 1977, COMO TAMBÉM À DECISÃO PROFERIDA NO AGRAVO DE INSTRUMENTO N. 0014521-23.2015.8.19.0000 de 10 de junho de 2015.

Entre os tratados e resoluções que a Defensoria mobiliza para justificar esse tipo de recomendação, passou a figurar uma decisão judicial bastante recente. Como sempre fazem constar em nota de rodapé, tal decisão remete à Ação Civil Pública (ACP) que foi elaborada pela Defensoria e apresentada à $10^{\text {a }}$ Câmara Cível do TJRJ, visando a compelir a Seap a cumprir a lei no que se refere ao banho de sol de seus custodiados. Os relatórios que registravam violações a esse direito foram utilizados para instruir a ACP, o tribunal de justiça foi mobilizado e a administração penitenciária teve que prestar esclarecimentos e se defender.

Os desdobramentos do caso dão notícia das limitações de um processo de mobilização institucional como esse, que acabou servindo apenas para produzir uma jurisprudência a ser evocada como as demais leis, normas e convenções cotidianamente postas em suspensão pelo funcionamento ordinário das prisões fluminenses. Em todos os relatórios de inspeção feitos após a referida decisão, não há o menor sinal de que a Seap tenha modificado sua política de banho de sol, de modo que a sua validade segue sendo reivindicada pela Defensoria a cada relatório. Tal destino reverbera - em outra escala, não mais no plano das interações imediatas - ainda aquela fraqueza relativa da letra da lei diante da força imediata das autoridades pri- 
sionais. De um lado, o sistema carcerário não parece se sentir constrangido a cumprir a decisão judicial; de outro, o sistema de justiça não parece dispor de meios para, nessa escala de atuação, fazer dobrar a vontade dos gestores prisionais e impor um grau mínimo de colaboração. Tamanha independência da prisão frente às injunções do sistema de justiça diferencia radicalmente os processos de burocratização das prisões - de "entrada" da lei e do correspondente transbordamento para fora e para cima dos espaços de decisão - nos Estados Unidos e no Brasil ${ }^{10}$.

Sobre essa espécie de desequilíbrio que se estabelece entre a letra da lei e a autoridade prisional, mesmo nessas esferas mais altas de atuação, outro processo de mobilização é ainda mais eloquente. Dos documentos que analisei, dois deles tratam de visitas ao Instituto Penal Plácido de Sá Carvalho (IPPSC), no Complexo de Gericinó, feitas nos dias 24 de abril e 10 de outubro de 2017. Conforme os relatórios, tais inspeções foram realizadas pela equipe da Defensoria na qualidade de "representantes" designados pela Corte Interamericana de Direitos Humanos (doravante, "Corte") para monitorar a implementação, pelas autoridades estaduais, das medidas provisórias que ela havia determinado por meio de suas resoluções de 13 de fevereiro e 31 de agosto de $2017^{11}$.

No esforço de contextualizar esses relatórios tão singulares, com base na leitura das referidas resoluções, pude apurar os seguintes fatos: em 23 de janeiro de 2016, o Nuspen realizou uma inspeção no IPPSC na qual, como de costume, pôde verificar uma série de problemas gravíssimos, mas também um número desproporcional de óbitos recentes ${ }^{12}$. Em 30 de março, a Defensoria denunciou essa situação à Comissão Interamericana de Direitos Humanos (doravante, "Comissão"), que, em 19 de julho, prescreveu um conjunto de medidas cautelares ao estado do Rio de Janeiro. Ainda em dezembro de 2016, frente à persistente imobilidade da Seap, a Defensoria indicou à Comissão a necessidade de encaminhar o caso à Corte - daí que, em 13 de fevereiro de 2017, a Corte divulgou sua primeira resolução sobre a matéria. Em 24 de abril, a equipe da Defensoria, já designada como "representante dos beneficiários", fez a inspeção que mencionei, registrando no relatório que nenhuma medida estabelecida pela Corte havia sido tomada.

10. Para uma análise das dinâmicas que se estabelecem entre poderes judiciário e executivo, sustentando situações análogas de suspensão da lei nas prisões paulistas, ver Zaffalon (2018).

11. Todas as resoluções da Corte estão disponíveis em https://sidh.cejil.org, consultado em 14/8/2019.

12. Não tive acesso ao relatório dessa inspeção em particular. Aqui, baseio-me no texto das resoluções. Sobre a mobilização em torno do IPPSC, ver ainda http://www.defensoria.rj.def.br/noticia/ detalhes/4685-Corte-Interamericana-de-Direitos-Humanos-inspeciona-presidio e http://defensoria.rj.def.br/noticia/detalhes/8621-CIDH-Um-dia-de-pena-devera-valer-por-dois-no-Placido-de-Sa-Carvalho, consultados em 14/8/2019. 
Então, em 19 de junho de 2017, uma comissão especial da Corte se deslocou ao Rio de Janeiro para uma "diligência in situ”, realizando uma visita ao IPPSC da qual participou uma plêiade de autoridades: além do célebre Juiz Raúl Eugenio Zaffaroni, do diretor jurídico da Corte e de um secretário, o próprio "titular" da Seap e alguns de seus colaboradores diretos, assim como o secretário e alguns assessores da Secretaria Estadual de Direitos Humanos, Políticas para Mulheres e Idosos (SEDHMI); também dois juízes do TJRJ ligados à área penal, e três promotores de justiça, membros das assessorias de direitos humanos, tutela penitenciária e execução penal do MP; e mais ainda, da esfera federal, o assessor de direitos humanos do Ministério de Relações Exteriores (MRE) e as assessorias internacionais do Ministério de Direitos Humanos ( $\mathrm{MDH}$ ) e da Advocacia Geral da União (AGU). Como “representantes dos beneficiários", além da conhecida equipe da Defensoria, o subdefensor público geral, o coordenador de defesa criminal e os coordenadores do Nuspen e do NUDEDH. Difícil conceber uma mais alta, externa e ampla arregimentação de forças.

Em 31 de agosto, a segunda resolução da Corte foi divulgada e, em 10 de outubro, a equipe da Defensoria fez uma nova vistoria para averiguar a implementação das medidas prescritas, sendo, na ocasião, secundada pelo MEPCT, pelo Instituto dos Estudos da Religião (Iser), pelo Instituto de Defesa dos Direitos Humanos (DDH) e pelo Instituto de Cultura e Consciência Negra Nelson Mandela. Na conclusão do relatório dessa inspeção se lê:

VIII - Considerações Gerais.

Pelo que foi verificado pelo NUDEDH, o Estado brasileiro não realizou qualquer ação substancial para o cumprimento das medidas da Resolução da Corte Interamericana de Direitos Humanos de 31 de agosto de 2017, que basicamente ratificou as medidas da Resolução de 13 de fevereiro deste mesmo ano.

O Instituto Penal Plácido de Sá Carvalho apresenta condições lastimáveis para o cumprimento de pena restritiva de liberdade. Suas instalações e serviços contrariam não só a Lei de Execução Penal e a Constituição Federal, como também tratados internacionais e qualquer outro princípio democrático ou dispositivo que tente ser usado para interpretar ou legitimar o disposto sobre a pena privativa de liberdade. $\mathrm{O}$ ambiente de total insalubridade, as condições impostas pela superlotação e a conjuntura deplorável em que figura a saúde de todo o efetivo fazem com que as pessoas privadas de liberdade lá acauteladas sejam completamente extirpadas de sua dignidade.

Em 22 de novembro de 2018, uma nova resolução da Corte sobre a matéria foi expedida, reafirmando integralmente as medidas previamente sugeridas e acrescentando outras - até o momento em que estas linhas são escritas não há notícia da 
adoção de medida alguma. Se, num certo plano de análise, aqui cabem questionamentos acerca das fragilidades do sistema internacional de direitos humanos para fazer valerem suas deliberações (Daems, 2017), em outro registro, e uma vez mais, avulta aquela soberana autoridade administrativa da prisão diante de uma debilíssima letra da lei - figurações essas que já se revelam características no decurso das inspeções. Mesmo uma das mais raras, vastas e altas arregimentações de forças para fazer "entrar" o direito na prisão esbarra na inércia e no poder manifesto de uma administração penitenciária impassível, só disposta a pequenas concessões, e não necessariamente a uma completa submissão às injunções da lei.

Para concluir estas reflexões e como corolário do argumento geral aqui esboçado, retomo, uma última vez, aquele relatório das visitas feitas ao Evaristo. Num excerto que versa sobre a segunda inspeção, constam as seguintes informações:

No dia 12 de maio de 2015, quando realizada vistoria conjunta da Defensoria Pública, Ministério Público e Mecanismo de Combate a Tortura da Alerj, não foi criado qualquer embaraço pelo novo diretor da Unidade, Sr. [NOME], que explicou que está provisoriamente no cargo em razão de promoção do antigo diretor que passou a exercer a função de coordenador do Complexo de Bangu. Foi utilizado material fotográfico, sem necessidade de autorização do Secretário da Secretaria de Segurança e Administração Penitenciária, em conformidade com a resolução do Conselho Nacional de Política Criminal e Penitenciária e franqueada a entrada da equipe em todas as celas sem qualquer tipo de embaraço ou itinerário definido unilateralmente.

A troca da direção do Evaristo entre os dias 30 de abril e 12 de maio de 2015 não se deu, portanto, porque o antigo diretor, que havia "maculado" o trabalho de fiscalização, não se mostrasse apto ao exercício daquela alta dignidade pública. O mesmo relatório que, em sua primeira recomendação, pede "abertura de Inquérito Policial, para apuração de eventual Crime de Abuso de Autoridade previsto nos artigos $3^{\circ}$ e $4^{\circ}$ da lei 4.898/65, por parte do ex-diretor", placidamente informa que ele fora promovido - e não afastado para garantir a devida apuração das responsabilidades, como seria de se esperar desde um ponto de vista burocrático-legal. Não só ele não "cai", como, pelo contrário, ele "sobe", ganha mais poder, torna-se o coordenador geral de todo o Complexo de Gericinó, ficando, portanto, responsável por quase metade do sistema carcerário fluminense, e tornando-se a autoridade cuja palavra servirá de esteio para a atuação de dezenas de outros gestores prisionais.

Mais do que ilustrar a impermeabilidade da prisão às injunções da lei, esse tipo de promoção indica que não só a imposição de uma racionalidade burocrático-legal pode deslocar os centros de poder e decisão para fora e para cima dos limites prisionais. Indica, portanto, que um estilo de gestão retrógrado e autoritário, avesso às 
formalidades da lei, pode também transbordar os muros da prisão e galgar posições na hierarquia administrativa.

Minha aposta é que as dinâmicas e relações aqui esboçadas poderão contribuir tanto para o fortalecimento de mecanismos institucionais de combate à tortura como o programa de monitoramento da Defensoria - quanto para a compreensão das circunstâncias que fazem com que as mais cruéis, desumanas e degradantes condições de confinamento vigentes nas prisões fluminenses tenham permanecido inalteradas, senão deterioradas, no decorrer das décadas. Talvez essas reflexões possam também ajudar a compreender como um estilo autoritário de gestão prisional, subindo e galgando posições, pode ter se convertido na forma atual de governar o país.

\section{Referências Bibliográficas}

Austin, John. (1962), How to do things with words. Londres, Oxford University Press.

BARAK-GLANTZ, Israel. (1981), “Toward a conceptual schema of prison management styles”. The Prison Journal, 61 (2): 42-60.

Cejus, Centro de Estudos sobre o Sistema de Justiça. (2015), IV Diagnóstico da Defensoria Pública no Brasil. Brasília, Ministério da Justiça.

Chantraine, G. \& Kaminski, D. (2008), "La politique des droits en prison: police institutionnelle, militantisme juridique, luttes démocratiques". Champ penal/Penal Field, Seminaire Innovations Pénales, https://journals.openedition.org/champpenal/2581, consultado em 14/8/2019.

Cliquennois, Gaëtan \& SNacken, Sonja. (2018), “European and United Nations monitoring penal and prison policies as a source of na inverted panopticon?" Crime, Law and Social Change, 70 (1): 1-18.

Cunha, Manuela. (2014), "The ethnography of prisons and penal confinement”. Annual Review of Anthropology, 43 (1): 217-233.

DAEMs, Tom. (2017) “Slaves and statues: torture prevention in contemporary Europe”. British Journal of Criminology, 57: 627-643.

DAs, Veena. (2007), Life and words: violence and the descente into the ordinary. Berkeley, University of California Press.

Depen, Departamento Penitenciário Nacional. (2016), Levantamento nacional de informaçôes penitenciárias. Brasília, Ministério da Justiça e Segurança Pública.

Feeley, Malcolm \& Swearingen, Van. (2004), "The prison conditions cases and the bureaucratization of American corrections: influences, impacts and implications". Pace Law Review, 24 (2): 433-475.

Foucault, Michel. (2014), Vigiar e punir. Petrópolis, Vozes.

Galembert, Claire \& Rostaing, Corinne, (2014), "Ce que les droits fondamentaux changent à la prison. Présentation du dossier”. Droit et Société, 87 (2): 291-203. 
Godor, Rafael. (2017a), Fluxos em cadeia: as prisões em São Paulo na virada dos tempos. São Paulo, Boitempo.

Godoi, Rafael. (2017b), “Tortura difusa e continuada”. In: MALlarT, Fábio \& Godoi, Rafael (orgs.). BR 111: a rota das prisões brasileiras. São Paulo, Veneta, pp. 117-126.

GuetzKow, Joshua \& Schoon, Eric. (2015), "If you build it, they will fill it: the consequences of prison overcrowding litigation”. Law \& Society Review, 49 (2): 401-432.

Gupta, Akhil. (2012), Red tape: bureaucracy, structural violence and poverty in India. Londres, Duke University Press.

JACOBS, James. (1980), “The prisoners' rights movement and its impacts, 1960-80”. Crime and Justice, 2: 429-470.

Jesus, Maria Gorete. (2010), O crime de tortura e a justiça criminal. São Paulo, IBCCrim.

Jesus, Maria Gorete et al. (2016), Jurisprudência do crime de tortura nos tribunais de justiça do Brasil (2005-2010). Revista de Estudos Empiricos em Direito, 3 (1): 79-97.

Kaminski, Dan. (2002), "Les droits des détenus au Canadá et en Angleterre: entre révolution normative et légitimation de la prison". In: SchutTer, Olivier \& KAMINSKI, Dan. (orgs.). L’institution du droit pénitentiaire: enjeux de la reconnaissance des droits des détenus. Paris/ Bruxelles, LGDJ/Bruylant, pp. 91-112.

Malvezzi Filho, Paulo. (2018), “Entre engrenagens e mecanismos: para uma crítica das políticas de prevenção da tortura no sistema prisional”. In: PASTORAL CARCERÁRIA. Tortura em tempos de encarceramento em massa. São Paulo, CNBB, pp. 76-88.

MARQUes, Adalton. (2018), Humanizar e expandir: uma genealogia da segurança pública em São Paulo. São Paulo, iBCCrim.

Morgan, Rod. (2000), "Developing prison standards compared”. Punishment \& Society, 2 (3): 325-342.

Relatório de Visita à Unidade Prisional Evaristo de Moraes. 30 de abril e 12 de maio de 2015. SAlla, Fernando. (2005), “O Brasil e o protocolo facultativo à Convenção das Nações Unidas contra a Tortura”. Revista Brasileira de Ciências Criminais, 57 (13): 213-247.

Salle, Grégory \& Chantraine, Gilles. (2009), “Le droit emprisonné? Sociologie des usages du droit em prison". Politix, 87: 93-117.

SCHOENFELD, Heather. (2010), "Mass incarceration and the paradox of prison conditions litigation”. Law \& Society Review, 44 (3/4): 731-768.

Simon, Jonathan. (2013), "Courts and the Penal State: lessons from California's decades of prison litigation and expansion”. California Journal of Politics and Policy, 5 (2): 252-265.

STANChi, Malu \& Dias, João. (2018), "Necropolítica nas prisões cariocas: análise das tecnologias de produção da morte a partir dos relatórios de vistoria da Defensoria Pública do Estado do Rio de Janeiro". Paper apresentado no IV Seminário Internacional de Pesquisa em Prisão. Dourados, Universidade Federal da Grande Dourados. 
Teixeira, Alessandra. (2009), Prisóes da exceção: política penal e penitenciária no Brasil contemporâneo. Curitiba, Juruá.

Zaffalon, Luciana. (2018), A politica da justiça: blindar as elites, criminalizar os pobres. São Paulo, Hucitec.

ZYL SMit, Dirk van. (2010), "Regulation of prison conditions". Crime and Justice, 39 (1): 509-563.

\section{Resumo}

\section{A prisão fora e acima da lei}

As fronteiras da prisão também erodem quando centros de poder e decisão se deslocam para fora dos muros e para cima de estruturas administrativas; quando injunções legais crescentemente condicionam as atividades do staff prisional, e o interior do cárcere é, cada vez mais, devassado por mecanismos diversos de prevenção e combate à tortura e outros tratamentos ou penas cruéis, desumanos e degradantes. A partir de análise qualitativa dos relatórios produzidos pela Defensoria Pública do Rio de Janeiro, no âmbito de seu programa de monitoramento do sistema carcerário, procuro discernir dinâmicas que caracterizam esse mais amplo processo neste contexto específico, bem como informam sobre seus alcances e limites.

Palavras-chave: Prisão; Tortura; Direitos humanos; Defensoria Pública; Rio de Janeiro.

\section{Abstract}

The prison outside and above the law

A process of erosion of prison boundaries also occurs when centers of power and decision move outside the walls and into higher administrative structures, when legal injunctions condition prison staff activities, and when the interior of the prison is increasingly monitored by various mechanisms for preventing and combating torture. In analyzing the reports of the Rio de Janeiro Public Defender's Office, made by its prison system monitoring program, I seek to identify dynamics that characterize that broader process in this particular context, as well as inform about its scope and limits.

Keywords: Prison; Torture; Human rights; Public Defender's Office; Rio de Janeiro.

Texto recebido em 15/8/2019 e aprovado em 31/8/2019.

DOI: $10.11606 / 0103-2070 . t s .2019 .161053$

RAFAel gODOI é mestre e doutor em sociologia pela Universidade de São Paulo, pós-doutorando no Programa de Pós-graduação em Sociologia e Antropologia da Universidade Federal do Rio de Janeiro e pesquisador do Núcleo de Estudos da Cidadania, Conflito e Violência Urbana (Necvu).E-mail: rafael.godoi@usp.br. 